\title{
PROFESSIONAL DEVELOPMENT AND ORGANISATION
}

\author{
DN Conco, DENOSA; \\ FM Mulaudzi, University of Pretoria; \\ E Seekoe, University of Fort Hare; \\ L Netshikweta, University of Venda
}

\begin{abstract}
This article provides an overview and history, as well as outlining the aims, objectives and organizational structure of the Democratic Nursing Organisation of SA (DENOSA). The role and responsibility of DENOSA as a professional association is delineated in relation to social policy development, service and practice affairs, nursing education and professional advancement, research, socio-economic welfare and its trade union wing. The history of the national nursing association in the country since 1944 leading to the establishment of DENOSA in 1996 is also briefly described. The objectives and structures are outlined, and the national, regional and international networks to which the organization belongs, identified. The roles and responsibilities of the organisation are then critically analyzed and illustrated with regard to current projects. In conclusion, the challenges faced by the organization are mentioned.
\end{abstract}

Keywords: Distance learning; Education; Nursing

\section{Introduction}

International trends suggest that professional organizations or national nursing associations (NNAs) play a critical role in unifying nurses as a collective group (Muller, 2009). In any particular country, the vibrancy of a NNA influences the trust and confidence which society has in the nursing profession. With this in mind, the Democratic Nursing Organization of South Africa (DENOSA) was established in 1996 as a voluntary organization for South African nurses and midwives, with the aim of unifying South African nurses. More recently, on the $25^{\text {th }}$ of July 2011, DENOSA was registered as a non-profit organization (registration number 091-645-NPO) by the Department of Social Development under the Non-Profit Organisation Act, \# 71 of 1997. Constitutionally, DENOSA is governed by a national board that includes provincial committees (Muller, 2009). Inasmuch as the constitution describes the current legal status of DENOSA, there is also a unique and interesting political history concerning how this organization has managed to mobilize and organize nurses in South Africa. This article provides an overview and outlines the history, aims, objectives and organizational structure of DENOSA. The role and responsibility of DENOSA as a professional association is delineated in relation to social policy development, service and practice affairs, nursing education and professional advancement, research, socio-economic welfare and its trade union wing.

\section{Historical background leading to the establishment of DENOSA}

DENOSA was launched on the $5^{\text {th }}$ of December 1996, even though there were already a number of professional organisations in the country such as the South African Nurses' Association (SANA). SANA was the most prominent organisation, established simultaneously with the South African 
Nursing Council (SANC), the regulatory body of nursing and nursing practice in South Africa, as outlined in the Nursing Act of 1944. The two nursing structures (SANA and SANC) were statutory nursing bodies. Hence it was compulsory for all practising nurses to be members of SANA and licensed by SANC (Vlok, 1988).

Historically and politically, it is well known that, in 1948, a South African white-dominated political dispensation implemented an apartheid system. Naturally, this system also had an impact upon the nursing profession. The SANC, like other white-dominated institutions, followed the apartheid regime by favouring the training of White nurses at well-equipped hospital schools and later nursing colleges. Black nurses experienced harsher conditions within poorly resourced hospital settings, nursing homes and educational environments. Additionally, during this era, an increased number of Afrikaans-speaking young women entered the nursing profession. The increase in numbers was part of a scheme to entrench apartheid policies in nursing. However, the dominant ideology of white superiority did not succeed in suppressing the achievements of African nurses. In competitive state nursing examinations, African nurses achieved excellent results which undermined the assumption of racial inferiority as perpetuated by the apartheid system.

In accordance with the segregation policies which were the cornerstone of apartheid, the government passed further discriminatory legislation in the form of the Bantu Homelands Citizenship Act of 1970. This Act created ten homeland territories: Gazankulu, Lebowa, KwaNdebele, KaNgwane, KwaZulu, Qwaqwa, Transkei, Bophuthatswana, Venda and Ciskei, segregating 'black' South Africans. Additionally, the Act limited the legal citizenship of 'black' South Africans to ethnic groups (Muller, 2009). Despite the fact that these homelands were putatively designed to be independent, in real terms they remained subordinate to, and dependent on, the Republic of South Africa economically, politically and administratively (De Beer, 1986). It is important to note that even though the KwaZulu Government (ZG) refused independence, the SA republic still governed it like a homeland.

This separation of state was also endorsed by the National States Constitution Act 21 of 1971 which declared that legislation of the Republic of South Africa was not applicable to Black homelands (Vlok, 1988). To align the nursing profession with the political developments, the SANC enacted the Nursing Act 50 of 1978 which pronounced SANA to be a professional nursing association for nurses practising within the republic, thus excluding those in the homelands. The exclusion from SANA of nurses practising under homeland administrations led to the formation of ten nursing professional associations The 'non-white' nurses employed by Provincial Administrations, including those in the Cape, Natal and Transvaal remained under the SANA. While most homelands established regulatory bodies as well, some remained under the SANC. For example, it was compulsory for nurses employed by ZG to affiliate with the KwaZulu Nursing Organisation (KNO), even though they were regulated by the SANC. To ensure coordination of the various organizations, the League of Nursing Associations of Southern Africa (LONASA) was formed in October 1982 (De Beer, 1986). LONASA's aim was to promote development of the nursing profession in Southern Africa (LONASA, 1982) What is more, this was to be achieved without any involvement of one association in the affairs of other member associations. However compliant with the political milieu, SANA policies prohibited nonwhite nurses from holding official positions within the organization. Because of these racially motivated activities, SANA lost its membership of the International Council for Nursing in 1989.

The SANA, as the prominent NNA, had enjoyed its statutory status until it became apparent that the 1993 interim SA Constitution was going to be approved. The constitution provided for "the establishment of one sovereign state, a common South African citizenship and a democratic system 
of government committed to achieving equality between men and women and people of all races" (SA Interim Constitution,1993). This meant that homelands would dissolve and the SANA would have to merge with the other nursing organisations. Parliamentary recognition that the SANA had enjoyed during the apartheid era was not guaranteed. Evident in minutes of the board meetings is an apprehension that organisational assets would not be safe should a succeeding government repeal the statutory status of SANA (SANA, 1994). Detrimental financial, organizational and human resource consequences were anticipated. These were some of the arguments that were used to persuade SANA leaders to secure a non-statutory and voluntary organizational status as a matter of urgency (SANA, 1995).

At the same time, South African nurses were uniting, getting organized and forming a collective that was dedicated to transforming the profession in line with apparent political developments. There was a move towards creating one professional organization that would be based on democratic principles- voluntary in nature, led and managed by nurses, and able to embody both trade unionism and professionalism. At a constitutional conference in 1996, with delegates representing diverse South African nursing groups, an overwhelming number of nurses voted for one NNA named DENOSA which was to be guided by a new constitution (Muller, 2009). The delegates approved the transitional arrangements whereby a Transitional Nursing Committee (TNC) was set up to steer the profession towards a united, voluntary NNA and the various nursing organizations, including LONASA, were dissolved. The assets of all the splinter associations were then transferred to DENOSA.

\section{Aims and objectives of DENOSA}

The aim of DENOSA was to "unite, empower, educate and support nurses as well as to influence health policy at various settings including local, regional and international forums". This aim was in harmony with the organization's vision, internal and external mission statements and values (DENOSA, 2011). The DENOSA Strategy of 2011-2015 articulated a mission statement that pronounced: "Nurses united in pursuing service excellence" (DENOSA, 2011). The internal mission was to support, represent and develop members as the backbone of South African health care and the external mission was to set forth "an empowered nursing cadre, serving, caring and advocating for society". The organizational values included excellence and professionalism, accountability, transparency, collectivism, leadership development (including empowerment), organizational growth, diversity, integrity and loyalty, as well as democracy and visibility" (DENOSA, 2011).

The organizational constitution put forward the following objectives:

1. To organize and unite all nurses in both public and private sectors;

2. To build a democratic worker-controlled organization based on membership participation in policy and decision-making;

3. To safeguard and promote the dignity, rights and socio-economic status of members through collective bargaining and other available legitimate means;

4. To recruit and unite all nurses into one organization;

5. To advance members' individual and collective interests through collective bargaining, and other legitimate means and forms of struggle;

6. To defend and protect members against any acts of unfair labour practices and threats to their job security; 
7. To play an active role in the fight against gender discrimination in the workplace and at a societal level;

8. To develop a strong shop steward movement sustained by quality and working-class- biased education and training;

9. To promote professional integrity and high standards of ethical conduct among members and in the health profession;

10. To promote equal access to healthcare by the general populace of South Africa;

11. To participate in, seek to influence and lobby all relevant policy-making bodies and institutions in the health sector, both nationally and internationally;

12. To develop and maintain contacts and relationships with other trade unions, trade union federations and organizations in pursuance of maximum working-class unity and solidarity, nationally and internationally;

13. To promote or oppose, as the case may be, any laws and administrative procedures that affect the interests of the members;

14. To undertake any other measures that might promote or be in the interests of the Organization and its members, and which are consistent with the aims and objectives of the constitution (DENOSA Constitution, 2010).

Related to the constitutional objectives, the organization strives to transform approaches that are integral to the design and development of innovative and socio-economically relevant courses and learning programmes through the objectives that are stated below:

- Contribute to leadership development and management in collective bargaining, nursing and healthcare;

- Influence national policy in collective bargaining, nursing and healthcare;

- Provide research productivity and support in collective bargaining, nursing and healthcare.

\section{DENOSA's Organizational Structure}

DENOSA has individual membership and is funded by membership fees and other income-generating activities. The organizational structure of DENOSA encompasses the appointed and elected officials. The appointed staff include a general secretary and two deputy general secretaries. The term of office for elected persons is four years. Therefore, every four years, DENOSA holds a national congress where delegates with voting powers elect their national leaders; namely, the president, two deputy presidents and the treasurer. Similar procedures are followed at provincial, regional and local offices where leaders are elected. The national congress may, by majority vote, approve changes to the constitution. Congresses also afford members the opportunity to discuss and resolve organizational policy matters. Similar provision is made every two years in Central Executive Committee (CEC) Meetings (DENOSA Strategy Document, 2010). 


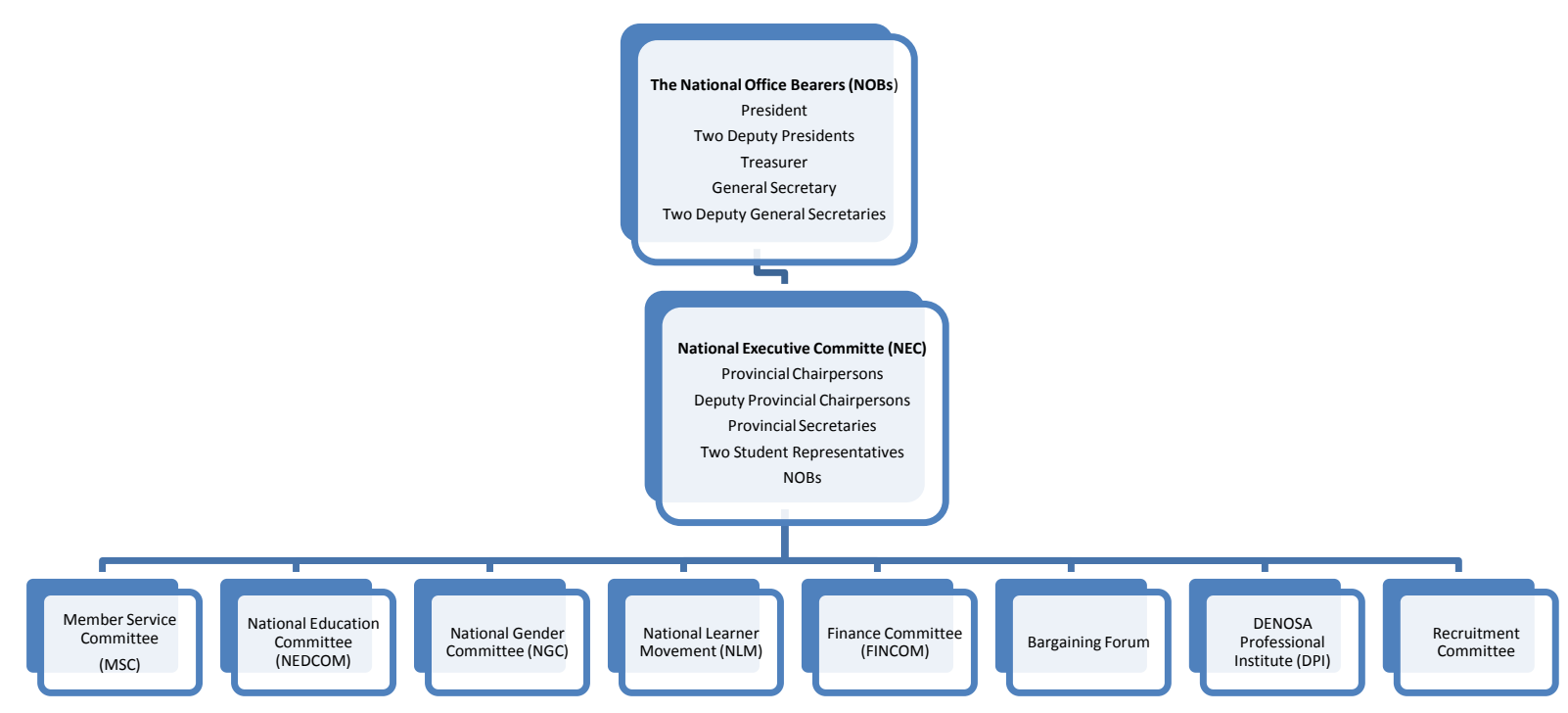

Figure 1.1: Organizational Structure

Even though organizational operations are administered and managed by appointed officials, the highest decision-making powers lie with the National Executive Committee (NEC). The NEC is constituted by three representatives from each province, two representatives of the National Learner Movement and the National Office Bearers (NOBs) i.e. the president, two deputy presidents, treasurer, general secretary and two deputy general secretaries. The constitution prescribes three NEC meetings per year, to be chaired by the president. The NEC may appoint subcommittees (see organogram) to fulfill organizational objectives in line with national congress resolutions. To ensure coordination, each subcommittee enlists at least one NEC member and is chaired by an NOB member, while the president and the general secretary retain ex officio membership of all subcommittees. Similar structures are duplicated at provincial, regional and branch levels in the nine South African provinces (DENOSA Strategy document, 2010). DENOSA owns a building in Pretoria that houses its head-office, and has offices in the provinces for regional offices.

\section{DENOSA's position locally, regionally and internationally}

The socio-political changes in the healthcare system necessitated that DENOSA collaborate with, and connect nurses in South Africa to, the rest of the world. Such collaboration needs to be achieved while balancing the dual mandate of being a professional association and a trade union. DENOSA therefore invests significantly in maintaining strong links with influential organizations, locally, regionally and internationally that may have a direct or indirect effect on the nursing profession. The choice of local, national and international affiliates assists DENOSA in achieving its objectives.

Internationally, DENOSA is affiliated to the International Council of Nurses (ICN) and the Commonwealth Nurses Federation. The regional collaboration involves organizations such as the Southern African Network of Nurses and Midwives (SANNAM), the East, Central and Southern African Health Community (ECSA), the East, Central and Southern Africa College of Nursing (ECSACON) and the African Health Profession Regulatory Collaborative for nurses and midwives (ARC). 


\section{International Council of Nursing (ICN)}

During the apartheid years, the SANA was the only association in South Africa, but it was expelled from the International Council of Nurses (ICN). During that time, the rationale that SANA gave was that it was discontinuing its membership with the ICN because of exorbitant affiliation fees. However, the truth was that the SANA was expelled based on political pressure from other countries who felt that the apartheid system should be abolished. After South African democracy, the newly formed DENOSA was readmitted to, and became a full member of, the ICN on 15 June 1997. Nurses in South Africa are currently enjoying all the benefits of being affiliated to the ICN. The latter has a three- pronged objective: the promotion of professional practice, as well as the regulation and socio-economic welfare of its members. One of the major achievements that has occurred since that time was the opportunity for DENOSA to host an ICN biennial congress in Durban in 2007. This was the first time that the ICN was hosted on the African continent. The conference was very successful, attended by 500 delegates from 118 countries. It raised awareness of nursing in Africa and assisted in ensuring recognition for the status of nursing in South Africa (Muller, 2009). Simultaneously, the conference offered the majority of SA nurses an opportunity to share their research findings with international colleagues and also to listen and take part in academic and leadership debates. Such encounters uplift the standard and also the status of nursing in South Africa to a global level.

\section{Regional collaboration}

DENOSA is affiliated with the Southern African Network of Nurses and Midwives (SANNAM) and also with the East, Central and Southern Africa College of Nursing (ECSACON).This was a way to honor the commitments of the South African Government to other African countries. SANNAM as an organization was launched on the 23 May 2001, following a meeting held by national nursing associations of the SADC countries after the 13th International HIV/AIDS Conference in Durban. The main aim was to collaborate in order to fight HIV/AIDS. SANNAM is a strong organization which fosters the work of 15 SADC countries to date.

Another regional establishment is the East, Central and Southern African Health Community (ECSA). This is a regional intergovernmental organization set up in 1974 to promote the highest possible standards of health among member countries. Currently, the region is made up of 10 member countries. These are Kenya, Lesotho, Malawi, Mauritius, the Seychelles, Swaziland, Tanzania, Uganda, Zambia and Zimbabwe. The organization later formed the East, Central and Southern African College of Nursing (ECSACON) which is a professional body for nurses and midwives in the East, Central and Southern African (ECSA) region. Botswana and South Africa joined the membership of ECSACON in 1998 (http://www.ecsa.or.tz/vacancies.php accessed 2/ 05/2013).

In addition to the two regional bodies already mentioned, a new body referred to as the African Health Profession Regulatory Collaborative for nurses and midwives (ARC) also collaborates with DENOSA The African Health Profession Regulatory Collaborative for Nurses and Midwives (ARC) is a four-year partnership between the CDC, the Commonwealth Secretariat, the Lillian Carter Center for Global Health and Social Responsibility at Emory University, and the East, Central and Southern Africa Health Community. ARC is aimed at advancing regulatory frameworks, strengthening organizational capacity and developing nursing and midwifery leadership. The model used to meet the objective of ARC entails a process of collaboration between organizations with similar interest to learn and share best practices aimed at improving the nursing status of the country. In this case, the 
collaboration entails the East, Central and Southern Africa health community (ECSA). The countries currently involved in this project are: Botswana, Ethiopia, Kenya, Lesotho, Rwanda, South Sudan, South Africa, Uganda, Zimbabwe and Zambia, The focus is on forming nursing quads to look at issues of regulatory frameworks and continuing education in the respective countries. The quad is formed by nurses occupying the highest office, representing the Government, Nursing Education, Nursing Association and Regulatory Body of the particular country.[http://www.cdc.gov/globalaids/SuccessStories/ARC2.pdf accessed 2.5.2013]

\section{Local collaborations}

In South Africa, DENOSA collaborates with National and Provincial Departments of Health, the South African Nursing Council (SANC), professional societies or bodies like the Forum of the University Nursing Deans of South Africa (FUNDISA), the Nursing Education Association (NEA) and the Society of Midwives of South Africa (SOMSA). DENOSA is also associated with health professional associations e.g. the South African Medical Association, research institutions such as the Human Sciences Research Council, University Departments, as well as national offices of United Nations' agencies like the World Health Organization (WHO). Other affiliates are the Health Science Academy, JHPIEGO, Soul City, SERITI Institute, AIDS Convention, Positive People's Network, AIDS Consortium, SANTRUST, Wits School of Public Health and Wits Reproductive Health and HIV Institute (WRHi).

\section{Roles and responsibilities of DENOSA}

Given the history of segregation in SA that obviously had an impact on the nursing profession, it became important for DENOSA, as the most prominent NNA, to embrace the responsibility of uniting nurses and to play a leading role in transforming the profession. This section explores the functions of the organization which, in summary, seek to develop both nurses and nursing. Not all DENOSA functions have a direct link to nursing education. However, it can be argued that most of its functions somehow contribute to nursing education, training and development. Its roles and responsibilities can be divided into two broad categories - the professional development and the socio-economic welfare role. While some activities will easily fall under one of the categories, some functions could border on both. Then again, DENOSA has always made an effort to balance professionalism with trade unionism, even though at some stage there was an outcry from nurses that the organization was concentrating more on the union rather than the professional wing.

\section{- Professional Developmental Role}

DENOSA has upheld the professional development role inherited from the LONASA era and has been commended for its efforts in preparing current and future nurses in South Africa. Its ultimate aim is to enhance and further professional growth to the benefit of all South Africans. The organization believes in keeping nurses abreast with changes, fostering a caring attitude within the profession, as well as enabling nurses to render a high level of service. DENOSA provides its members with relevant updated health and professional international information, disseminating updates on global health issues affecting members and their country. This is done through publications such as "Nursing Update", which is a monthly professional news magazine, and also through their website.

Continuing education is an important aspect of nursing. Through its institute for professional development, DENOSA ensures that development of nurses and the nursing profession remains an important aspect of the organization. It was therefore important for the organization to respond to 
the outcry that the professional wing was compromised. The response entailed reviving and relaunching its institute for professional development in 2011. It is now referred to as DENOSA Professional Institute (DPI) and its main focus is on education, training and development. DPI activities were informed by the results of a situational analysis that was conducted to determine skills' gaps among nurses. Current DPI learning programmes include: Tuberculosis/MDR-TB Management training for Nurse Educators in partnership with the University Research Council (URC), HIV and AIDS Management, Community Health Worker Training a Dispensing Course in conjunction with the Health Science Academy (HSA), adherence to ART in conjunction with HAS, Computer Literacy for Nurses, Quality of Care \& Professional ethos, and Labour Relations - Basic \& Intermediate Shop-Stewards' Training. Beyond learning programmes DENOSA is involved in a number of activities, discussed below, that are in line with professional development.

\section{Bringing an international leadership program to South African nurses}

Leadership abilities are critical in managing health service delivery. Yet these skills are not covered in the formal training of most health professionals, although nursing management is included in the basic training programme of nurses. The strategic leadership issues which can equip nurses to become leaders in hospital management and other fields in the healthcare systems are not covered. The ICN has identified a global need to train nurses as leaders by initiating Leadership for Change (LFC) as an accredited action learning programme to develop nurses as effective leaders and managers in a constantly changing health environment. The LFC programme is designed to address the leadership gap apparent in the formal education and training of nurse managers. The specific objective is to develop nurse leaders and managers in health services who will have the ability to:

- Influence policy and health system improvements;

- Develop quality, cost-effective models of delivering services;

- Be effective contributors to the broader healthcare team.

The overall objective is to strengthen the capacity for nursing leadership and management in health services so that a group of nurses at senior and middle management levels of the health services are better equipped to improve the quality of professional care and also to meet other critical challenges facing the health sector. People from this group will help train others in a "second generation" programme, thus enhancing the capacity for making an impact across the entire healthcare system (DENOSA, 2012). The programme is currently offered in 150 countries both internationally and in Africa. The target group includes all nurses who are involved in strategic management functions such as: Chief Nursing Officers, Heads of Department (Nursing), CEOs (Nursing), Nursing School Principals, Hospital Nurse and District Nurse Managers.

\section{Biannual South African Nurses Conference}

DENOSA encourages and support its members to attend both national and international conferences. It also hosts national conferences biennially to create a platform to share information and display the good work and research conducted in nursing. DENOSA hosted the first South African Nurses' Conference from the $16^{\text {th }}$ to the $17^{\text {th }}$ of March 2011 at the Sandton Convention Centre. The conference deliberations and recommendations complemented proposals submitted to the Ministerial Nursing Summit of 2011. The second conference is scheduled to take place from the $16^{\text {th }}$ to the $18^{\text {th }}$ of October 2013 at Inkosi Albert Luthuli Convention Centre, Durban (DENOSA, 2009). 


\section{DENOSA Brown Bag Lunch Seminars}

DENOSA is also hosting Brown Bag Lunch Seminars (BBLS) at the headoffice in Pretoria to communicate to its members. The seminars offer nurses an opportunity to deliberate and discuss current developments in health policy. This is in line with the organization's commitment to advance nurses' capacity to interrogate and influence policy. The objective is to build a pro-active nursing body capable of initiating and providing leadership in policy issues. Experts are invited to share their knowledge and expertise on many topics relating to health. Researchers are also invited to share their findings with an audience of practitioners, scholars and nurse leaders (DENOSA, 2009).

\section{Library and archives}

Nursing heritage, especially the archives, forms an important part of the history of the country. DENOSA inherited nursing archives which are kept in the library under the management of a fully qualified librarian. The library has been revamped and is being developed in line with a vision to make it the biggest nursing library in the African region. DENOSA also boasts e-library facilities that are accessible both at national and provincial offices. The library plays a critical role in keeping nurses up to date and well informed about current policy issues that may affect the profession (DENOSA, 2012). The association has also kept the record of the NNA since its inception in 1944.

\section{Accredited Journal}

Through DENOSA, nursing knowledge is advanced by encouraging members to become involved in research and continuous teaching in all focus areas specified in the ten-point plan of the Department of Health. DENOSA also promotes scholarship in nursing by offering health researchers the opportunity to publish their articles in a peer-reviewed journal referred to as Curationis. Curationis is an open access journal which is quite highly rated internationally, with an impact factor of 0.9. It provides a forum for cutting-edge theories and research models related to the exploration of issues such as nursing and midwifery best practice so as to improve nursing education, nursing administration and community nursing within Africa.

\section{- Advocacy and Policy Role}

DENOSA's contribution to social policy development is evidenced by its advocacy role for the position of nursing in the country, in collaboration with the Lily MDR-TB partnership to support the best practice for quality patient care. Nurse's Day is celebrated annually. Themes are provided nationally to observe the birth of the founding philosopher of modern nursing, Florence Nightingale.

One of the main functions of DENOSA is its advocacy role. It acts as a mouthpiece for the profession by emphasizing the need for the creation of an enabling environment for healthcare practitioners, stressing the importance of empowering healthcare practitioners and developing effective reporting systems. The importance of capacity-building and development of management skills, as well as the involvement of various stakeholders and government monitoring in issues relating to ensuring optimum delivery of quality healthcare services is also emphasized (DENOSA: 2013). The professional organization/association acts in the interests of the nursing practitioner as an individual or group (Muller, 2009). DENOSA demonstrates its role by acting as a facilitator in problems that an individual or a group may have regarding services. It acts as a mediator in terms of disputes where services are affected. 
As a professional organisation/association, DENOSA acts as a facilitator in problems that affect its members as individuals or groups (Muller, 2009: 54). It acts on behalf of patients where issues of quality compromise nursing care. DENOSA, along with SAMA (the South African Medical Association) advocated for Positive Practice Environments, a project to assist the Department of Health in improving conditions in health institutions countrywide (DENOSA \& SAMA, 2013-2015). They both emphasized the safety of healthcare professionals in the workplace, improvement in payment of salaries, mechanisms to ensure that equipment used by health professionals is serviced regularly and replaced, provision of basic services necessary for professionals to carry out their work and provision of human, financial and material resources for the smooth running of health facilities. Education and support of healthcare professionals and respect for their rights (Positive Practice Environment Campaign for Health Professionals, 2013-2015) were also stressed.

The association has a responsibility to set quality standards of practice, acting as a mouthpiece regarding problems in practice and providing solutions, without undermining the employer's authority. DENOSA demonstrates its role by being part of healthcare service committees, forums and workshops at national and international levels. The association provides input in drafting discussion documents, promulgation of legislation, regulation directives, policies and strategies in health matters (DENOSA: 2013). DENOSA also develops and publishes policy statements. The National Care Standards and Competencies is one such policy statement. DENOSA showed its proactive stance in its media statement of February 2013 where it applauded the Minister for prioritizing health infrastructure in re-engineering Primary Health Care Services and preparing for the implementation of the National Health Insurance. This professional organisation/association contributes to the promulgation of laws governing health and the profession. It is often consulted by the Department of National Health on innovation, continuous quality improvement and operational research.

\section{- DENOSA's Socio-Economic Welfare role}

DENOSA has both a professional and trade union wing. The latter is responsible for the promotion of the organization's social welfare role. It recruits and unites all nurses into one organization in order to advance members' individual and collective interests through collective bargaining and other legitimate means and forms of protest. Salary negotiations by DENOSA are done at the level of professionals, not general workers. It does not negotiate a blanket fee/amount for salary increases, but takes different professional and salary scales into consideration, as opposed to other organizations where all are regarded as workers. Service conditions of its members are a priority. An example of this role is shown where DENOSA acts as a legal body representing members in cases of disputes between employee and employer. It negotiates better conditions of employment for its members (DENOSA, 2013).

DENOSA's professional credibility is underscored by virtue of its being consulted when the National Health Department needs support regarding issues of nursing and health services (Muller, 2009)

Although DENOSA has its roots in unionism and represents the workplace interests of its members, the organization took notice of global developments amongst nursing unions in order to include professional development of its members as part of its core focus. To this end, the DENOSA Congress of 2007 took a decision to re-introduce professional development activities as part of the DENOSA 
offering. DENOSA inherited a dual mandate of professionalism and trade unionism and adopted a constitution that underpins all organizational endeavors. Muller (2009: 57) describes a trade union as a collection of employees in a particular organization, profession or industry who are united for the purpose of representing their interests in the workplace and society. Nurses have a democratic right to belong to any trade union: however, DENOSA is an exclusive trade union for nurses by nurses. Its mandate is to strengthen the profession and talk to its members. To this end, the DENOSA Professional Institute (DPI) was established in September 2009 with generous funding provided by Atlantic Philanthropies. This grant augmented the internal DENOSA funding used for the programme.

DENOSA is not the only trade union for nursing professionals, as nurses have the choice to register with either COSATU-affiliated or non-COSATU affiliated unions. DENOSA's membership numbers are extremely important as they affect its bargaining power with employers and, ultimately, DENOSA's credibility as a union. Currently, DENOSA has enough members to be represented in the Public.

Although nurses have other nursing organizations such as the South African Democratic Nursing Union (SADNU), Health and other Personnel Trade Union of South Africa (HOSPERSA), National Education. Health and Allied Workers' Union (NEHAWU) etc., the majority of nurses in South Africa belong to DENOSA which remains the prominent NNA in South Africa. DENOSA is a registered trade union which is affiliated with the Congress of South African Trade Unions (COSATU). On the $24^{\text {th }}$ of February 1998, DENOSA registered as a trade union (reference number LR2/6/3/682) in terms of section 96(7) (a) of the Labour Relations Act, 1995.

DENOSA continues to be concerned by the challenges faced by the nursing profession in our country. Nursing, the backbone of health services, faces massive challenges, arguably more than those confronting any other profession in the health sector. These challenges include the very same poor working conditions that we have always been vocal about, the issue of school leavers who lack an interest in pursuing nursing as a profession due to the inhuman work environment, and the issue of safety and security in hospitals (Fongqo, 2011).

DENOSA is a member-driven organisation, calling on all its members to take ownership and participate fully in the activities of the organisation, thereby acting as agents for change in our challenging profession. Be proud of being a nurse! Take care of yourself and your profession! Never stop working to be at the forefront of your profession. DENOSA also experiences challenges regarding the implementation of bargaining agreements. On many occasions, for example, DENOSA has had to enforce the implementation of the occupation-specific dispensation (OSD) for nurses, especially in the National Department of Correctional Services, through a costly court process. The Occupation Specific Dispensation (OSD) agreement was reached in 2007, and yet the employer has applied every possible tactic to frustrate and delay the implementation of this award.

\section{Conclusion}

This chapter described the brief history of a nursing organization in South Africa - the formation of DENOSA, along with its roles, functions and milestones as an organization that strives to achieve the empowerment and mobilization of nurses into a formidable power base, actively engaged in the strategic objectives to unify nursing as a profession. In its mandate it has managed to uphold the standard of education and training for the development of leadership, quality care and empowerment of its members and staff. In terms of the challenges nurses are faced with within the 
healthcare environment, DENOSA strives to inculcate professional culture in nurses and utilisation of nurse specialists. The trade union wing is based on collective bargaining which assists in increasing the bargaining power, resolving of disputes and reviewing of agreements. Being part of collective bargaining also assists DENOSA in forming political networks which are necessary to ensure that nurse leaders become involved in political dialogue at all levels so that they can influence policies on health and labour matters. The organization has also managed to establish nursing in South Africa within the global arena by making sure that South African nurses are part of the International Council of Nursing. International collaboration is also emphasised and encouraged to intensify collaboration and networks with international partners.

DENOSA works with different stakeholders to ensure that advances in the past that have an impact on the nursing profession, nursing education and research, as well as the current changes and challenges that are changing the face of healthcare and the projected discoveries that will change the future of healthcare today, be taken into consideration. DENOSA endorses this approach as one which will have positive spin-offs that may potentially resolve the disarray currently experienced in the country's depots. Poor working conditions, long and inconvenient working hours, uncompetitive salaries and limited professional development opportunities for nurses need to be addressed. Enhancing the image of nursing and creating a harmonious workplace where a multigenerational nursing workforce feels valued will improve retention. It should be realised that healthcare has changed and will continue to change for the better. Nurses in this country should be constantly aware of changes that occur in the nursing profession.

\section{References}

De Beer, C. 1986. The South African Disease: Apartheid Health and Health Services. Nottingham: Africa World Press.

DENOSA, 2010. Democratic Nursing Organisation of South Africa Constitution. Pretoria.

DENOSA, 2011. Democratic Nursing Organisation of South Africa Strategic Plan 2011-2015. Pretoria.

DENOSA, 2012. Democratic Nursing Organisation of South Africa Central Executive Committee: DPI Report. Pretoria.

DENOSA, 2013. Positive Practice Environment Campaign for Health Professionals 2013-2015. Democratic Nursing Organisation of South Africa. Pretoria.

Delihlazo, S. 2013. Media Relations. Communication Department. Democratic Nursing Organisation of South Africa: Pretoria.

Fongqo, A. 2011. Nurses 'must be held accountable' for patient abuse. City Press. 10 (8): 12.

Gwagwa, T. 2010. Nurses united shall never be defeated, DENOSA GS tells SANNAM symposium. Pretoria, SADC region: South Africa.

LONASA, 1982. Constitution of the League of Nursing Associations of Southern Africa. Pretoria. 
Madonda, N. 2013. International Relations. DENOSA. Democratic Nursing Organisation of South Africa: Pretoria,.Muller, M. 2009. Nursing Dynamics. Fourth Edition, Johannesburg: Heinneman.

SANA, 1986. The South African Nursing Association in Committee November 1986 - February 1995 Minutes. Pretoria.

SANA, 1994. The South African Nursing Association Central Board Meetings March/ April 1994 Minutes. Pretoria.

SANA, 1994. The South African Nursing Association Central Board Meetings June 1994 Minutes. Pretoria.

SANA, 1994. The South African Nursing Association Central Board Meetings July/August 1994 Minutes. Pretoria.

SANA, 1994. The South African Nursing Association Central Board Meetings June 1994 Minutes. Pretoria.

SANA, 1995. The South African Nursing Association Central Board Meetings May/July 1995 Minutes. Pretoria.

Vlok, M.E. 1988. Manual of Nursing Volume I-Basic Nursing. Cape Town: Juta\& Co. 